УДК 621.18 .01

\author{
РАЗРАБОТКА И ОПЫТ ЭКСПЛУАТАЦИИ \\ ГОРИЗОНТАЛЬНОГО ВОДОГРЕЙНОГО КОТЛА КВ-ГМ-55-150 \\ Орумбаев Р.К., Кибарин А.А., Коробков М.С., Ходанова Т.В. \\ Алматинский университет энергетики и связи, Алматы, e-mail: kibarin@rambler.ru
}

\begin{abstract}
Настоящая статья посвящена проблемам разработки экономичных сейсмостойких водогрейных котлов. Существующую проблему для районов с повышенной сейсмичностью авторы предложили решить, разработав сейсмостойкие горизонтальные конструкции водогрейных котлов КВ-ГМ тепловой мощностью 35-55 МВт с размещением их в зданиях котельных высотой до 9,0 м, т.е. значительно ниже существующих зданий котельных с серийными вертикально ориентированными водогрейными котлами. В работе показано, что разработанные авторами горизонтальные водогрейные котлы работают экономично и надежно с 2011 г. в ряде котельных г. Алматы. Тепловые испытания, проведенные на котле № 5 котельной «Акселькент», подтвердили высокие технико-экономические показатели работы котла. Тепловая мощность котла в процессе испытаний изменялась от 25,18 МВт (21,71 Гкал/час) до 49,6 МВт (42,77 Гкал/час), расход газа калорийностью 8289,3 ккал/м ${ }^{3}$ варьировался от $2700 \mathrm{~m}^{3} /$ час до $5566 \mathrm{~m}^{3} /$ час. Избыток воздуха $\alpha$ в уходящих газах составил соответственно от 1,36 до 1,16 . На номинальной нагрузке по результатам экстраполяции экспериментальных данных температура уходящих газов составила $160^{\circ} \mathrm{C}$, а КПД брутто котла $92,5 \%$. В настоящее время по результатам теплотехнических испытаний водогрейный котел доработан, в топочной камере установлен дополнительный двухрядный огибающий экран, который позволил заметно улучшить тепловые характеристики котла за счет интенсификации теплообмена и снизить температуру уходящих газов за котлом с увеличением КПД котла до уровня 93-93,5\% на номинальной нагрузке.
\end{abstract}

Ключевые слова: водогрейный котел, тепловые испытания, двусветный экран, радиационный и конвективный теплообмен, повышение надежности, эффективность работы

\title{
DEVELOPMENT AND OPERATION EXPERIENCE OF HORIZONTAL KV-GM-55-150 HOT-WATER BOILER
}

Orumbaev R.K., Kibarin A.A., Korobkov M.S., Khodanova T.V.

Almaty University of Power Engineering and Telecommunications, Almaty, e-mail: kibarin@rambler.ru

\begin{abstract}
The article is dedicated to problems of development of the economical efficient and seismic resistant hot-water boilers. This problem for high seismic level regions authors propose to solve by development of constructions of the seismic resistant horizontal KV-GM hot-water boilers of the heat power output of 35-55 MW. The location of boilers could be into the boiler houses with max high of $9 \mathrm{~m}$ and it is much lower than the conventional existed boiler houses with the typical vertical hot-water boilers. In the article is mentioned that developed horizontal hot-water boilers works with high levels of reliability and efficiency on the modernized boiler houses in Almaty city since 2011. Provided thermal tests of the boiler № 5 of «Aksel'kent» boiler house approved its high techno-economic operation parameters. During the tests the heat power output of the boiler were increasing from $25.18 \mathrm{MW}(21.71 \mathrm{Gcal} / \mathrm{hr})$ up to $49.6 \mathrm{MW}\left(42.77 \mathrm{Gcal} / \mathrm{hr}\right.$ ), gas flow (gas net heat value $8289.3 \mathrm{ccal} / \mathrm{m}^{3}$ ) measures were from $2700 \mathrm{~m}^{3} / \mathrm{hr}$ up to $5566 \mathrm{~m}^{3} / \mathrm{hr}$. Air excess level $(\alpha)$ of the flue gases was between 1.36 and 1.16 accordingly to the named power output rates. Results of the extrapolation of the experimental data of the boiler operation on nominal heat rate shows that the temperature of the flue gases is $160^{\circ} \mathrm{C}$ and the boiler efficiency rate brut is $92.5 \%$. Today based on thermal tests' results the hot-water boiler is modernized, into the furnace is placed additional two-rows round furnace screen that gives increase of thermal output parameters by the intensification of heat transfer and decrease the temperature of flue gases after the boiler with sufficient increase of boiler efficiency rate up to $93-93.5 \%$ on the nominal power rate.
\end{abstract}

Keywords: hot water boiler, thermal tests, bi-radiated furnace screen, radiation and convective heat exchange, reliability increase, work efficiency

В настоящее время большое количество устаревших конструкций водогрейных котлов средней мощности, эксплуатируемых в Республике Казахстан, имеют низкую эффективность и надежность. Основные конструкции водогрейных котлов КВ-ГМ и ПТВМ разрабатывались в середине прошлого века [1-4]. Замена более 130 водогрейных котлов средней мощности, таких как ПТВМ-30М, ПТВМ-100 и некоторых котлов серии КВ-ГМ с фактическим КПД от $89 \%$ до $90 \%$ [5], на новые эффективные и сейсмостойкие водогрейные котлы с более высоким КПД по Республике Казахстан позволит экономить до полумиллиона тонн условного топлива в год и значительно сократить удельные выбросы токсичных и парниковых газов.

Цель исследования: опытная оценка теплотехнических характеристик новых горизонтальных водогрейных котлов КВ-ГМ-55-150, разработанных авторами по техническому заданию ТОО «АТКЭ», с целью увеличения единичной мощности и плановой замены морально устаревших котлов серий ПТВМ-30МС, ПТВМ-50 и ПТВМ-100.

Водогрейные котлы ПТВМ имеют башенную компоновку и значительную высоту до 17,6 м. Для обслуживания башенных 
водогрейных котлов требовались высокие здания, и в сейсмической зоне до 9 баллов они оборудовались мощным сейсмостойким несущим каркасом. При этом расход металла возрастал до $100 \%$ к весу металла собственно котла, что приводило к существенному удорожанию с учетом увеличения стоимости монтажных работ. Поэтому давно существовавшую проблему для сейсмических районов авторы предложили решить, разработав сейсмостойкий горизонтальный водогрейный котел КВ-ГМ-55 с размещением его в здании высотой всего до 9,0 м, т.е. значительно ниже существующих зданий котельных с серийными вертикально ориентированными водогрейными котлами, в том числе и ПТВМ-50.

Новая конструкция водогрейного котла своими нижними коллекторами (камерами) опирается непосредственно на фундамент специальными «скользящими» упорами вместе с конвективной частью. На рис. 1 приведен общий вид нового водогрейного котла КВ-ГМ-55-150 и каркас котельной высотой всего 9 м в свету.

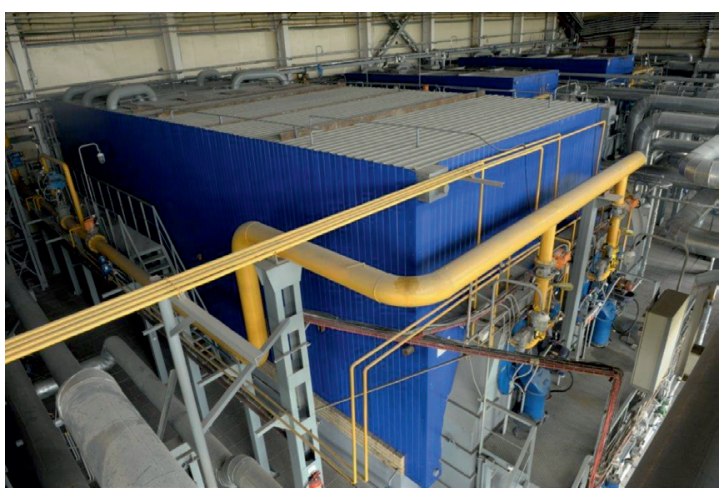

Рис. 1. Общий вид нового водогрейного котла KB-ГM-55-150

Нижние коллекторы боковых экранов на расстоянии до 8 м от фронтового экрана фиксируются анкерными болтами к фундаменту. Появлялась возможность теплового расширения топочной части котла в сторону фронта при работе, а всей конвективной тыльной стороны расширяться в сторону газохода котла. Газоход котла выполнен с тепловым компенсатором, и вторая часть свободно расширяется в тыльную сторону котла.

Общая гидравлическая схема водогрейного котла КВ-ГМ-55 запатентована действующими Патентами РК $[6,7]$. Циркуляция воды в водогрейном котле по [6] осуществляется двумя параллельными потоками с общим расходом воды через котел до 658 (700) м м ччас по 329 (350 м $3 /$ час) по каждой симметричной стороне водогрейно- го котла от топки и по всей конвективной части котла.

Для обеспечения доступа ко всем трубным поверхностям нагрева под первой и второй конвективными частями выполнены люк-лазы, защищенные и оформленные теплоизоляционной обмуровкой.

На фронтовом экране параллельно установлены две газо-мазутные горелки РГМГ-30 (РФ), факелы которых развиваются горизонтально в сторону тыла топки и перпендикулярно омывают трубы поворотного экрана ударяются о цельносварные трубы тыльного экрана и, проходя нижние фестонные трубы, оказываются под конвективными пакетами труб первой конвективной части. Далее газовый поток поднимается и омывает шахматные конвективные пакеты труб первой конвективной части по противоточной схеме и в верхней части, проходя через разведенные трубы промежуточного фестонного экрана, опускается и обтекает шахматные конвективные трубы второй конвективной части и по газоходу с тепловым компенсатором выводятся за пределы котла.

\section{Материалы и методы исследования}

Для проведения теплотехнических испытаний водогрейного котла № 5 КВ-ГМ-55-150 в котельной «Акселькент» были выполнены подготовительные работы по оснащению измерительными приборами, термометрами, термопарами с вторичными приборами, газоанализатором и с компьютерным дублированием (АСУ ТП) измеряемых характеристик котла на восьми режимах по тепловой мощности в соответствии с типовыми методиками испытаний.

Котел КВ-ГМ-55 был запущен в эксплуатацию в октябре 2011 г. и выведен на режим с расходом воды $\mathrm{G}=658 \mathrm{т} /$ час, $\left(\mathrm{t}_{1}=63^{\circ} \mathrm{C}, \mathrm{t}_{2}=128^{\circ} \mathrm{C}, \mathrm{t}_{\mathrm{yx}}=154^{\circ} \mathrm{C}\right)$, гидравлическое сопротивление котла составило порядка 0,23 МПа $(2,3$ кгс/см²), КПД $=92,86 \%$ при тепловой мощности 49,61 МВт $(42,77)$ Гкал/час. В соответствии с потребностью микрорайонов вокруг котельной «Акселькент» (г. Алматы) тепловая нагрузка котла соответствовала расчетным проектным показателям. Результаты испытаний и эксплуатационные показатели работы котла практически совпали с расчетными результатами разработчиков конструкции котла, а также с проектными показателями.

Новая компоновка из двух рядом расположенных конвективных частей с пакетами из труб диаметром $\varnothing 32 \times 3$ мм реализована в идентичных конструкциях горизонтальных водогрейных котлов КВ-ГМ-35, КВ-ГМ-40 и КВ-ГМ-50. В новой компоновке двух конвективных частей, как в первой части, так и во второй части, поток воды и продуктов сгорания были выполнены по схеме противотока, которые позволяли поддерживать высокий уровень температурного напора и, соответственно, теплоотдачи от газового потока к трубам по всей высоте двух конвективных пакетов труб. Скорость воды в каждом ходе конвективных труб изменялась варьированием числа рядности труб в пакетах и в зависимости от скорости омываемого газового потока. 
Фронтовой, два боковых, верхний, нижний, поворотный и тыльный экраны позволили создать симметричную конструкцию $[6,7]$. Экраны выполнялись цельносварными, мембраны (плавники) поочередно были смещены в противоположные стороны от диаметральной плоскости между трубами с шагом $\mathrm{s} / \mathrm{d}=1,4(\mathrm{~d}=57 \times 4$ мм) по [8]. Смещенные поочередно в противоположные стороны от диаметральной плоскости мембраны (плавники) топочных экранов обеспечивали более равномерный прогрев по периметру экранных труб. В новой конструкции цельносварных экранов котлов с поочередно смещенными мембранами эпюры изгибающих моментов, возникающих из-за неравномерного прогрева по периметру труб, частично уравновешиваются, так как направлены в противоположные стороны. Цельносварной экран с поочередно смещенными в разные стороны от диаметральной плоскости мембранами [8] образует жесткую конструкцию. Собранные таким образом экраны обеспечивают достаточную плотность в топке и делают конструкцию котла более прочной и практически невосприимчивой к хлопкам и взрывам в объеме топки, и тем более к переменным тепловым нагрузкам.

В водогрейном котле КВ-ГМ-55 в наиболее теплонапряженной части поворотного экрана в топке экранирующего и защищающего собой фестонный экран, движение воды выполнено только восходящим, что допускает значительное форсирование теплового напряжения в топке на расчетных топливах. Конструкция котла с наиболее теплонапряженными экранами, в которых выполняется подъемное движение воды, является наиболее надежной с точки зре- ния эксплуатации котла в реальных условиях работы. Максимальный достигнутый при испытаниях расход воды через котел КВ-ГМ-55 составляет $658 \mathrm{~m}^{3} /$ час при перепаде давлений на входе и выходе $0,35 \mathrm{MПа,}$ при этом номинальный расход воды через обычный вертикальный водогрейный котел КВ-ГМ-50 составляет $618 \mathrm{~m}^{3} /$ час.

Котел КВ-ГМ-55 проработал семь отопительных сезонов в автоматическом режиме вместе со вспомогательным оборудованием (АСУ ТП) и с поддержанием мазутного хозяйства котельной в рабочем состоянии. Изменений, деформаций, течей и конденсации воды на поверхности труб экранов, пакетов и коллекторов до настоящего времени обнаружено не было.

В процессе испытаний тепловая мощность котла изменялась от 25,18 МВт (21,71 Гкал/час) до 49,6 МВт (42,77 Гкал/час), расход газа калорийностью 8289,3 ккал/м ${ }^{3}$ варьировался от $2700 \mathrm{~m}^{3} /$ час до $5566 \mathrm{~m}^{3} /$ час. Избыток воздуха $\alpha$ в уходящих газах составил соответственно от 1,36 до 1,16 , а содержание окиси углерода СО в уходящих газах было ноль процентов. Качество сжигания контролировалось анализом газа непрерывно.

На рис. 2 представлены сравнительные характеристики по отношению конвективной поверхности $\mathrm{H}_{\kappa}$ к радиационной поверхности $\mathrm{H}_{\mathrm{p}}$ для водогрейных котлов с классической компоновкой $[1,9-11]$ и для нового водогрейного котла с горизонтальной компоновкой. Сравнение показывает совпадение значений отношения конвективной поверхности к радиационной поверхности, что показывает правильность соотношений количества тепла воспринимаемого конвективной и радиационной частями котлов.

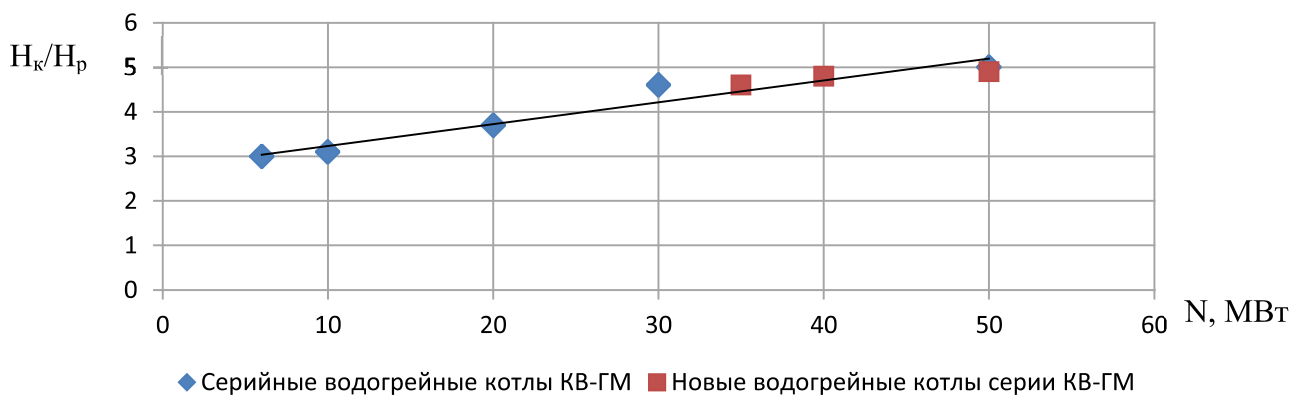

Рис. 2. Сравнительные характеристики по отношению $H_{\kappa} \kappa H_{p}$ для серийных и новых водогрейных котлов

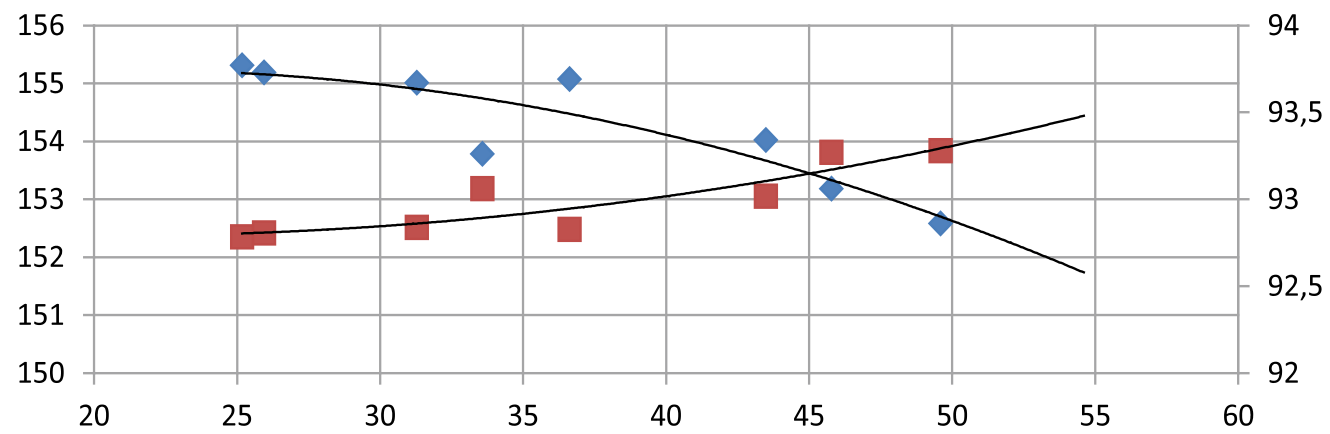

Удельный расход условного топлива, кг.у.т./Гкал

Рис. 3. Основные эксплуатационные теплотехнические характеристики КВ-ГМ-55 
Совпадение значений по рис. 2 доказывает правильность выполненных тепловых расчетов для новых водогрейных котлов с горизонтальной компоновкой, основанных на нормативных правилах и формулировках и подтверждающих действующие закономерности лучистого и конвективного теплообмена в котлах.

На рис. 2 приведены данные для новых водогрейных котлов КВ-ГМ-35, КВ-ГМ-40 и КВ-ГМ-55. Связь между тепловой мощностью котла и отношением $\mathrm{H}_{\mathrm{K}} / \mathrm{H}_{\mathrm{p}}$ можно представить в виде линейной зависимости

$$
\mathrm{H}_{\mathrm{\kappa}} / \mathrm{H}_{\mathrm{p}}=0,05 * \mathrm{~N}+2,7,
$$

которая хорошо согласуется с проектными данными серийных и новых водогрейных котлов типа КВ-ГМ.

Сравнение показывает, что отношение общей поверхности нагрева $\Sigma$ Н к тепловой мощности $N$ новых котлов выше на 13-15\%, чем у традиционных водогрейных котлов, в диапазоне по тепловой мощности выше 30 МВт и до 70 МВт. Это позволяет существенно расширить возможности по увеличению тепловой производительности и снизить тепловую нагрузку поверхностей нагрева котла в топочной камере при номинальных нагрузках, а также увеличить срок службы котлов при соблюдении правил эксплуатации и консервации при сезонном простое.

На рис. 3 приведены показатели по коэффициенту полезного действия $\eta$ (брутто) котла и удельному расходу условного топлива. Полученные экспериментальные данные в целом совпадают с расчетными характеристиками разработчиков котлов и результатами моделирования в программе BOILER DESIGNER [12].

\section{Результаты исследования и их обсуждение}

Экстраполяция результатов экспериментов на номинальную нагрузку показывает, что температура уходящих газов составляет $160{ }^{\circ} \mathrm{C}$, а КПД брутто котла $92,5 \%$. Что значительно выше большинства ныне эксплуатируемых котлов в системе котельных АО «АТКЭ» $[5,13]$.

Опыт эксплуатации первых шести водогрейных котлов КВ-ГМ-55 и КВ-ГМ-35 начиная с 2012 г. в котельных «Акселькент» и «Елисейские поля» (г. Алматы) в системе ТОО «АТКЭ» при работе на природном газе с АСУ ТП показал, что в процессе эксплуатации поддерживается высокий уровень КПД, низкий уровень вредных и парниковых газов, при соблюдении в хорошем состоянии поверхностей нагрева котлов. За период эксплуатации новых котлов (9 штук) до настоящего времени квалифицированный персонал соблюдает и выполняет жесткие требования по соблюдению режимов, по качеству питания котлов химически очищенной водой, а также грамотно проводит консервацию котлов в летний период вынужденного простоя.

В настоящее время в г. Алматы успешно работают три водогрейных котла новой компоновки КВ-ГМ-55 и шесть водогрейных котлов КВ-ГМ-35 и КВ-ГМ-40. На основные типоразмеры водогрейных котлов серии КВ-ГМ мощностью до 145 МВТ разработаны новые технические условия (СТП), зарегистрированные в АГУЧС города Алматы и Госстандарте (г. Астана).

В настоящее время авторами и разработчиками доработаны конструкции водогрейных котлов КВ-ГМ-55, КВ-ГМ-35 и КВ-ГМ-40, учтены все особенности и замечания эксплуатирующих организаций. В топочной камере установлен дополнительный двухрядный огибающий экран, являющийся дополнительной радиационной поверхностью и увеличивающий интенсивность дожигания газового факела. Эффективность применения двусветных экранов в водогрейных котлах подробно рассмотрена в работах [13-16]. Технические параметры котла доведены до следующих значений: радиационная поверхность нагрева составила $\mathrm{H}_{\mathrm{p}}=286,7 \mathrm{~m}^{2}$, конвективная поверхность нагрева $\mathrm{H}_{\mathrm{K}}=1406 \mathrm{~m}^{2}$, объем топки $\mathrm{V}_{\mathrm{T}}=313,3 \mathrm{~m}^{3}$. Установка дополнительно двухрядного огибающего экрана перед поворотным экраном в конце топки позволила заметно улучшить тепловые характеристики котла за счет интенсификации теплообмена и снизить температуру уходящих газов за котлом с увеличением КПД котла [6] до уровня 93-93,5\% на номинальной нагрузке.

В настоящее время в рамках грантового финансирования Комитета Науки МОН РК по проекту АР № 05133388 продолжается обобщение опыта эксплуатации новых эффективных водогрейных котлов средней и малой тепловой производительности на примере котлов КВ-ГМ-40, КВ-ГМ-35, КВ-ГМ-55, КВ-ГМ-7,56, КВ-ГМ-3,65 и серии котлов КСГн.

\section{Выводы}

В системе ТОО «АТКЭ» успешно эксплуатируются водогрейные котлы нового поколения КВ-ГМ-55, КВ-ГМ-40, КВ-ГМ-35, которые по основным параметрам - тепловой мощности, маневренности, надежности, экономичности, КПД и удельным выбросам вредных веществ в атмосферу превосходят аналогичные конструкции водогрейных котлов.

Результаты наладочных и режимных теплотехнических испытаний подтвердили основные расчетные параметры заложенные разработчиками в конструкцию горизонтального водогрейного котла КВ-ГМ-55. На номинальной нагрузке по результатам экстраполяции экспериментальных данных температура уходящих газов составила $160^{\circ} \mathrm{C}$, а КПД брутто котла $92,5 \%$. Опыт эксплуатации показал, что в процессе работы поддерживается высокий уровень КПД, 
низкий уровень вредных выбросов и выбросов парниковых газов, при соблюдении в хорошем состоянии поверхностей нагрева котлов. В настоящее время по результатам теплотехнических испытаний водогрейный котел доработан, в топочной камере установлен дополнительный двухрядный огибающий экран, который позволил заметно улучшить тепловые характеристики котла за счет интенсификации теплообмена и снизить температуру уходящих газов за котлом с увеличением КПД котла до уровня 93-93,5\% на номинальной нагрузке.

\section{Список литературы}

1. Котлы водогрейные мощностью от 11,63 и до 209 МВт. Каталог для проектирования котельных. Т. 2. 4-е изд. Дорогобужкотломаш, 2007. 80 с.

2. Документация на котлы // Вебсайт АО «Дорогобужкотломаш» [Электронный ресурс]. URL: http://dkm.ru/documentation/documentation-for-boilers (дата обращения: 30.10.2018).

3. Бузников Е.Ф., Роддатис К.Ф., Берзиньш Э.Я. Производственные и отопительные котельные. 2-е изд., перераб. М.: Энергоатомиздат, 1984. 248 с.

4. Орумбаев Р.К., Орумбаева Ш.Р. Оценка экономического и экологического эффекта при замене морально устаревших водогрейных котлов в Республике Казахстан // Actual Problems of Economics. Киев. 2012. № 5. С. 38-43.

5. Дукенбаев К.Д. Энергетика Казахстана и пути ее интеграции в мировую экономику. Алматы: Гылым, 1996. 530 с.

6. Орумбаев А.Р., Орумбаева Ш.Р., Орумбаев Р.К. Водогрейный котел // Патент Республики Казахстан № 25337. Опубл. бюлл. № 12. от 20.12.2011 г.

7. ПОрумбаев А.Р., Орумбаева Ш.Р. и др. Водогрейный котел // Патент на полезную модель Республики Казахстан № 2864. Опубл. бюлл. № 21. от 16.06.2018 г.
8. Орумбаев Р.К., Чижов В.Э. и др. Водогрейный котел // Патент Республики Казахстан № 11229. Опубл. бюлл. № 2. от 15.02.2002 г.

9. Спильник Е.Р., Шемякин В.Н., Хоменок Л.А. Пути повышения энергоэффективности и улучшения эксплуатационных характеристик водогрейных котлов ПТВМ // Надежность и безопасность энергетики. 2012. № 3 (18). C. 44- 46 .

10. Orumbayev R.K., Khodanova T.V., Kibarin A.A., Korobkov M.S. Efficiency assessment of bi-radiated screens and improved convective set of tubes during the modernization of PTVM-100 tower hot-water boiler based on controlled all-mode mathematic models of boilers on Boiler Designer software. IOP Conference Series: Earth and Environmental Science. 2018. Vol. 136. Paper ID 012016.

11. Дахов А.И., Рязанев С.М., Страхов М.Ю. и др. Пути повышения производительности, надежности и экономичности водогрейных котлов ПТВМ-100: аналит. обзор. АлмаАта: КазНИИНТИ, 1989. 81 с.

12. Доверман Г.И., Мошкарин А.В., Шелыгин Б.Л., Мельников Ю.В. Расчет котельных агрегатов с использованием современных программных продуктов: учеб. пособие. Иваново ГОУВПО «Ивановский государственный энергетический университет им. В.И. Ленина», 2007. 220 с.

13. Барабаш В.В. Модернизация водогрейных котлов КВ-ГМ и ПТВМ: о внедренных технических решениях и новых разработках // Новости теплоснабжения. 2013. № 04 (152). URL: http://www.rosteplo.ru/nt/152 (дата обращения: 22.10.2018).

14. Лавренцов Е.М. Новые конструктивные решения при создании водогрейных котлов с высокими технико-экономическими показателями // Энерготехнологии и ресурсосбережение. 2007. № 1. С. 57-64.

15. Варичев О.В. Оснащение водогрейных котлов двусветными экранами // Электрические станции. 1977. № 7. C. $79-80$.

16. Овчинников В.А., Петриков С.А., Крылов А.К. Обобщение опыта эксплуатации водогрейных котлов ОАО Доробужкотломаш // Теплоэнергетика. 2011. № 12. С. 22-46. 